\title{
A ORALIDADE NA CONSTRUÇÃO DE UM ETHOS EDUCATIVO KAINGANG
}

ORALITY IN THE CONSTRUCTION OF AN EDUCATIONAL ETHOS KAINGANG

ORALIDAD EN LA CONSTRUCCIÓN DE UN ETHOS EDUCATIVO KAINGANG

\author{
Leonel Piovezana ${ }^{1}$; Fernanda Machado Dill²; Cláudia Battestin ${ }^{3}$; Anderson Luiz Tedesco ${ }^{4}$
}

\section{RESUMO}

A discussão central deste artigo, parte da reflexão sobre a constituição do ethos educativo Kaingang. Trata-se, portanto, de avaliar as relações que constituíram o ethos histórico, marcadas por intensas e violentas interações e contínuos projetos de dominação com os povos originários. Para tanto, a discussão teórica ocorre a partir do ethos histórico, cultural e comunitário, pois busca-se evidenciar os conhecimentos construídos a partir da tradição oral nas comunidades Kaingang, adotando a metodologia da história oral. Este estudo objetiva compreender como o ethos dos povos originários pode ser um lugar de aconchego, de motivos ancestrais, de princípios educativos que regem a vida, neste caso, dos povos Kaingang. Destaca-se entre os resultados que a constituição de um ethos educativo Kaingang, consiste em assegurar seu protagonismo, autonomia e sentido comunitário na construção do diálogo, respeito e reconhecimento ao ethos da pluralidade.

PALAVRAS-CHAVE: Ethos educativo. Povos Originários. Kaingang.

\footnotetext{
${ }^{1}$ Doutor em Desenvolvimento Regional - Universidade de Santa Cruz do Sul (UNISC). Santa Cruz do Sul, RS Brasil. Professor do Programa de Pós-graduação Stricto Sensu em Educação - Universidade comunitária da Região de Chapecó (Unochapecó). Chapecó, SC - Brasil. Líder do Grupo de Pesquisa SULEAR: Educação Intercultural e Pedagogias Decoloniais na América Latina - (Unochapecó). Chapecó, SC - Brasil. E-mail: leonel@unochapeco.edu.br

${ }^{2}$ Doutorado em Arquitetura e Urbanismo - Universidade Federal de Santa Catarina (UFSC). Florianópolis, SC Brasil. Atualmente realiza pesquisa em nível de Pós-doutorado na área de categorias de análise socioespacial em etapas pré-concepção no processo de projeto em arquitetura e urbanismo. Universidade Federal de Santa Catarina (UFSC). Florianópolis, SC - Brasil. E-mail: fernanda.dill@gmail.com

${ }^{3}$ Doutora em Educação - Universidade Federal de Pelotas (UFPel). Professora do Programa de Pós-graduação em Educação da Universidade Comunitária da Região de Chapecó (Unochapecó). Vice-líder do Grupo de Pesquisa SULEAR: Educação Intercultural e Pedagogias Decoloniais na América Latina - (Unochapecó). E-mail: battestin@unochapeco.edu.br

${ }^{4}$ Doutor em Filosofia Pela Pontifícia Universidade Católica do Paraná (PUCPR). Professor da Universidade Comunitária da Região de Chapecó (Unochapecó). Professor do Colégio La Salle de Xanxerê, SC. Membro do Grupo de Pesquisa SULEAR: Educação Intercultural e Pedagogias Decoloniais na América Latina - (Unochapecó) e do Grupo de Pesquisa em Educação, Violência e Democracia - GruPEV\UFFS. E-mail: anderson.tedesco@unochapeco.edu.br
}

Submetido em: 02/02/2021 - Aceito em: 06/07/2021 


\section{ABSTRACT}

The central discussion of this article is based on a reflection on the constitution of the Kaingang educational ethos. It is, therefore, about evaluating the relationships that constituted the historical ethos, marked by intense and violent interactions and continuous projects of domination with the original peoples. Therefore, the theoretical discussion takes place from the historical, cultural and community ethos, as it seeks to highlight the knowledge built from the oral tradition in the Kaingang communities, adopting the methodology of oral history. This study aims to understand how the ethos of the original peoples can be a place of coziness, of ancestral reasons, of educational principles that govern life, in this case, of the Kaingang peoples. It stands out among the results that the constitution of an educational ethos Kaingang, consists in ensuring its protagonism, autonomy and community sense in the construction of dialogue, respect and recognition of the ethos of plurality.

KEYWORDS: Educational Ethos. Original peoples. Kaingang.

\section{RESUMEN}

La discusión central de este artículo se basa en una reflexión sobre la constitución del ethos educativo Kaingang. Se trata, por tanto, de evaluar las relaciones que constituyeron el ethos histórico, marcado por interacciones intensas y violentas y continuos proyectos de dominación con los pueblos originarios. Por lo tanto, la discusión teórica se desarrolla desde el ethos histórico, cultural y comunitario, ya que busca resaltar el conocimiento construido a partir de la tradición oral en las comunidades Kaingang, adoptando la metodología de la historia oral. Este estudio tiene como objetivo comprender cómo el ethos de los pueblos originarios puede ser un lugar de calidez, de motivos ancestrales, de principios educativos que rigen la vida, en este caso, de los pueblos Kaingang. Se destaca entre los resultados que la constitución de un ethos educativo Kaingang, consiste en asegurar su protagonismo, autonomía y sentido comunitario en la construcción del diálogo, respeto y reconhecimento del ethos de pluralidad.

PALABRAS CLAVE: Ethos educativo. Pueblos Originarios. Kaingang.

\section{INTRODUÇÃO}

Este artigo aborda reflexões a respeito da constituição do ethos na história dos povos originários, mais precisamente do povo Kaingang. Trata-se, portanto, de pensar como as relações que constituíram o ethos histórico, foram marcadas por intensas e violentas interações e contínuos projetos de dominação para com os povos originários. Na perspectiva cultural, visualizamos um ethos potencialmente educativo, que indica caminhos epistemológicos capazes de dialogar com diferentes formas de ser e viver o mundo, alicerçados na cosmologia Kaingang.

Em busca de elementos que possam caracterizar a concepção de ethos, nos deparamos com inúmeras definições, o conceito pode ser entendido como morada, lugar, costumes, crenças que definem um grupo, coletividade ou comunidade. Uma alternativa é recorrer a própria etimologia do ethos. De acordo com Vaz, "o ethos encontra-se dividido em um ethos (com eta inicial) e um ethos (com épsilon inicial)" (2004, p. 12). Identifica-se que na primeira definição do ethos (com eta inicial), sua característica principal se manifesta como sendo a morada do ser; "este sentido de um lugar de estada permanente e habitual, de um abrigo protetor, constitui a raiz semântica que dá origem à significação do ethos como 
costume, esquema praxeológico durável, estilo de vida e ação" (VAZ, 2004, p. 13).

Essa forma de pensar o ethos como uma "casa simbólica" do ser humano, possibilita a compreensão dos aspectos culturais das mais diferentes etnias planetárias. É nesse acolhimento que o ethos enquanto morada humana assegura a cada povo sua singularidade, o que resulta em segurança, abrigo e proteção da existência da constituição do próprio sercultural. É também, nesta maneira de pensar que nos aproximamos de um conceito capaz de entender a diversidade em cada unidade, pois é exatamente neste ethos que se visualiza a cosmovisão Kaingang.

Esse espaço habitável pelo ser humano passa a ganhar forma por meio do ethos, uma vez que transformou a physis inscrevendo-se, "os costumes, os hábitos, as normas e os interditos, os valores e as ações" (VAZ, 2004, p. 13). Portanto, segundo o autor, "o ethos não é dado ao ser humano, mas por ele construído ou incessantemente reconstruído" (2004, p. 13). E é nisto também que consiste o ethos educativo, pois trata-se de uma construção coletiva dos sentidos e das subjetividades da vida na comunidade.

Tratar do conceito filosófico de ethos a partir da perspectiva Kaingang, é considerar que essa cultura em sua língua significa "Povo do Mato [...]a língua falada por esse grupo étnico constitui, ainda hoje, um dos mais importantes signos diacríticos de sua identidade, demonstrando que, apesar da violência do contato, da submissão deste povo e da equivocada política integracionista implementada pelo Estado brasileiro, mantiveram sua identidade étnica" (NACKE, 2007, p. 34). Quando apropria-se da metáfora do ethos como sendo a "casa espiritual" da humanidade, acredita-se que dela resulta a própria proteção simbólica de cada ser humano, imerso na cultura. Assim, esta que não é a casa material da humanidade, mas caracterizou-se em um ethos que nunca está pronto e acabado propriamente dito, ou seja, sempre em construção ou reconstrução. Esse desafio da incompletude, torna o ser humano inacabado, na constante busca de um ethos da acolhida na diversidade cultural, de um lugar no mundo.

Precisamente, tal concepção do ethos como "casa simbólica", resultou na compreensão e na tradução das próprias manifestações culturais das mais diferentes etnias do planeta; "o ethos é a morada do animal e passa a ser a "casa" (oikos) do ser humano, não já a casa material que lhe proporciona fisicamente abrigo e proteção, mas a casa simbólica que o acolhe espiritualmente" (VAZ, 2002, p. 40). A cultura acumula o que é conservado, transmitido, apresentado e comporta vários princípios de aquisição e programas de ação. $O$ primeiro capital humano é a cultura. O ser humano, sem ela, seria um primata do mais baixo escalão" (MORIN, 2007, p. 35). O ethos histórico, considera que a cultura precisa ser pensada, segundo Kuper (2002) como uma questão de ideias e valores, uma atitude mental coletiva. As ideias, valores, cosmologia, princípios morais, modo de viver, organização espacial e estética, são expressados por meio de símbolos, caracterizando a cultura como um sistema

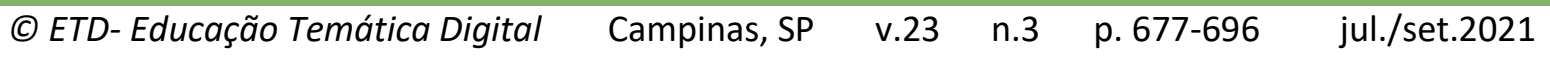


simbólico. A partir de inúmeras pesquisas etnográficas, Geertz expõe a complexidade das diversas culturas contemporâneas, que se entrelaçam e se obrigam a conviver, coloca que seu objetivo é "[...] abrir espaço para futuros culturais, para o reconhecimento do que surge [...]" (GEERTZ, 2001, p. 31). Segundo ele, isto requer uma crítica de hábitos mentais e valores ocidentais profundamente enraizados.

Neste sentido, em um primeiro momento constitui-se um breve arcabouço teórico, posteriormente as reflexões em decorrência dos relatos da história oral, por sua vez o artigo objetiva compreender aspectos da constituição do ethos Kaingang, cuja base da discussão parte de uma perspectiva educativa, pois ocorre com a socialização das oralidades dos indígenas, que asseguram seu protagonismo histórico e autonomia na construção das análises, abrindo-se para uma via do diálogo, do respeito e do reconhecimento na construção de um ethos da pluralidade. Tratam-se essas aberturas do ethos, de uma perspectiva educativa que se constitui na relação de intersubjetividade do ser-no-mundo e do ser-com-ooutro. Aqui, afirma-se, na compreensão vaziana, a ideia de horizonte do ser. O mundo é, para cada um de nós, o caminho para o encontro do outro" (VAZ, 1992, p. 74). Assim, chega-se ao momento eidético que, segundo $\operatorname{Vaz}$ (1992, p. 74), essa relação do eidos com a intersubjetividade busca compreender no "espaço conceptual delimitado pela pluralidade dos sujeitos e pela relação que estabelece entre a forma de uma unidade na pluralidade".

Ao assumir esse movimento dialético, chega-se à proposição de que "O Eu é um Nós" (VAZ, 1992, p. 75). Pensar nesta perspectiva, é pensar a unidade na diversidade, em que um depende do outro para sobreviver, para viver em comunidade e seguir cultuando as crenças, costumes e religiosidades. A morada, casa, lugar, representa para os Kaingangs a comunidade, o território e as territorialidades, pois é nesse ethos, que os saberes tradicionais habitam e tornam a educação, um lugar do eu e do nós!

\section{DO ETHOS HISTÓRICO AO ETHOS CULTURAL DOS POVOS ORIGINÁRIOS}

Buscamos nesta reflexão caracterizar alguns aspectos sobre o ethos histórico e cultural, considerando como premissa que os processos "civilizatórios" na América Latina planejados pelos espanhóis e portugueses foram constituídos pelo desprezo às identidades indígenas. Em nossa hipótese, não foram relações inocentes. Eles, os europeus (ditos civilizados) se apropriaram das novas terras e dos vários tipos de riquezas, não só materiais, mas subjetivas, simbólicas. Tal processo de invasão ocorre sob a proteção da coroa portuguesa ou espanhola e a benção da Santa Madre Igreja, uma vez que ambas as instituições autorizaram essas ações. Nas palavras de Bauman (2001), tais ações foram possíveis, porque "não se lançaram à tarefa no escuro, seu esforço tinha o poderoso apoio da imposição legal da língua oficial, de currículos escolares e de um sistema legal unificado [...]" (p. 199). 
Quando se recorre aos estudos do ethos histórico, antes mesmo dos "invasores" chegarem ao Brasil, Ribeiro observa que, "o Vaticano estabelece as normas básicas de ação colonizadora" (RIBEIRO, 2006, p. 35). Esse processo "civilizatório" foi assim denominado: "às novas cruzadas que não se lançavam contra hereges adoradores de outro Deus, mas contra pagãos e inocentes" (RIBEIRO, 2006, p. 35). Trata-se de considerar que "dentro das fronteiras do Estado só havia lugar para uma língua, uma cultura, uma memória histórica e um sentimento patriótico" (BAUMAN, 2003, p. 84). Portanto, posicionar-se em direção contrária a tal forma de pensamento hegemônico e monocultural, caracterizava-se como um risco cultural, pois se assumia a perseguição, a violência e a morte do próprio ethos.

O projeto para colonizar, implicava na tarefa de desumanizar, e através da dominação promover possibilidades de não reconhecer o outro como um sujeito de direitos e valores (CESAIRÉ, 1978). Os povos originários, foram subjugados pelos colonizadores. "Para os colonos, os índios eram um gado humano, cuja natureza, mais próxima de bicho que de gente, só os recomendava à escravidão" (RIBEIRO, 2006, p. 49). Tal subjugação étnica também se justifica em documentos religiosos. Observou-se na bula Romanus Pontifix, escrita pelo papa Nicolau V no dia 8 de janeiro de 1454 e na bula Inter Coetera escrita por Alexandre VI. Esses escritos papais revelam a autorização para se 'apossar' de todo território desconhecido, ou seja, uma nova construção do ethos nas Américas.

Neste projeto de colonização, não existe respeito pela Alteridade na diversidade, pois as "realizações individuais não podem solidificar-se em posses permanentes porque, em um piscar de olhos, os ativos se transformam em passivos, e as capacidades, em incapacidades". (BAUMAN, 2009, p. 7). Precisamente, o resultado da desconstrução do ethos no período da colonização deixou na história suas marcas, impondo um modelo educativo e religioso, representando, segundo Saviani (2011):

A posse e exploração da terra subjugando os seus habitantes (os íncolas); a educação enquanto aculturação, isto é, a inculcação nos colonizado das práticas, técnicas, símbolos e valores próprios dos colonizadores; e a catequese entendida como a difusão e conversão dos colonizados à religião dos colonizadores (p. 29).

As populações indígenas, paradoxalmente consideradas íncolas perderam o direito de ocuparem a suas próprias terras, pois tal apropriação foi concedida aos colonizadores. Isto se comprova com a criação da Lei no 28 , de 25 de abril. De acordo com o Artigo 4으 da presente Lei, seu objetivo era: "proteger, auxiliar e defender os moradores de qualquer assalto do gentio, malfeitores e fugitivos, perseguindo-os até seus alojamentos, quilombos ou arranchamento, fazendo todo o possível por prendê-los e, no caso extremo de resistência, destruí-lo (SANTOS, 1973, p. 66). Também não se pode esquecer a "guerra bacteriológica travada pelas pestes que os brancos disseminaram entre as etnias originárias. Elas, eram doenças mortais para as populações indígenas. 
No mesmo ano de 1562, por justos juízos de Deus, sobreveio uma grande doença aos índios e escravos dos portugueses, e com isto grande fome, em que morreu muita gente, e dos que ficavam vivos muitos se vendiam e se iam meter por casa dos portugueses a se fazer escravos, vendendo-se por um prato de farinha, e outros diziam, que lhes pusessem ferretes, que queriam ser escravos: foi tão grande a morte que deu neste gentio, que se dizia, que entre escravos e índios forros morreriam 30.000 no espaço de 2 ou 3 meses (ANCHIETA, 1933, p. 356).

Foram muitas mortes em que a causa eram as doenças. Mas, também a própria desapropriação das terras resultou em pobreza extrema. No plano ecológico, observou-se a disputa do território, de suas matas e riquezas para outros usos (RIBEIRO, 2006). Os estudos não são unânimes, com relação ao número de etnias indígenas dizimadas, mas sabe-se que as etnias originárias do tronco tupi guarani e outras: "somavam, talvez, 1 milhão de índios, divididos em dezenas de grupos tribais, cada um deles compreendendo um conglomerado de várias aldeias de trezentos a 2 mil habitantes" (RIBEIRO, 2006, p. 28). Entretanto, em nome do Religiosus e do Economicus, se destruiu a alteridade.

Se passaram mais de quinhentos anos e a tomada de consciência pouco parece ter mudado, tanto que para as populações que por séculos não tinham "direito a ter direitos ao teto, a terra, à saúde, à escola, à igualdade e à cidadania plena se fazem presentes em ações e movimentos, em presenças incômodas que interrogam o Estado, suas políticas agrárias, urbanas e educacional" (ARROYO, 2012, p. 09). Por isso, precisamente, a urgência de intensificar os debates sobre esses direitos negados às populações originárias, com objetivo consciente de pensar a reconstrução do ethos cultural como uma prática social e como um ato político.

Trata-se de pensar o ethos histórico numa condição de continuação, os novos valores são incluídos e passam a fazer parte da cultura. Entretanto, o ethos não morre, se transforma e é transmitido de geração em geração. Nesta linha interpretativa, quando se constrói uma reflexão sobre o ethos nas culturas dos povos originários, constata-se que muitos não tiveram a possibilidade de continuação de sua existência, pois o projeto perverso de "colonizar" a américa, destruiu o ethos, a morada, a cosmologia e o lugar de ser e existir de culturas que desconhecemos a existência. Outrora, a oralidade é uma das formas de salvaguardar as cosmologias, que ainda existem e resistem por séculos de opressão.

\section{A ORALIDADE NA CONSTITUIÇÃO DO ETHOS COMUNITÁRIO}

Na cultura indígena, a oralidade é fundamental para compreender aspectos profundos da própria constituição do ethos. Ela traduz aquilo que pode ser considerado como mais sagrado entre os povos, pois trata-se da própria "comunidade que produz uma sensação boa por causa dos significados que a palavra comunidade carrega [...]" (BAUMAN, 2003, p. 7). Por sua vez, a oralidade é o caminho de caracterização da essência da comunidade, também traduzida como sendo o "lugar confortável e aconchegante. É como um teto sob o qual nos 
abrigamos da chuva pesada, como uma lareira diante da qual esquentamos as mãos num dia gelado" (BAUMAN, 2003, p. 7). Não é retórica quando os povos Kaingangs por exemplo, afirmam que a terra é a mãe, que a natureza é a vida, que sem ela o filho morre, é exatamente o lugar aconchegante que Bauman traduz, pois remete a segurança, acolhida, sobrevivência e subsistência, um lugar que acolhe e supre todas as necessidades para a seguir sendo ethos.

É neste lugar de ser, no espaço do ethos, que o povo Kaingang resistiu diante das mazelas e manteve, através da oralidade, do testemunho, da palavra e do silêncio, a sua cosmologia latente, por isso:

\begin{abstract}
A importância do testemunho oral pode estar muitas vezes, não no seu apego aos fatos, mas antes em sua divergência com eles, ali onde a imaginação e o simbolismo desejam penetrar. A história não é apenas sobre eventos, ou estruturas, ou padrões de comportamentos, mas também sobre como são eles vivenciados e lembrados na imaginação. A construção de uma memória coletiva pode resultar numa força histórica por si só de imenso poder (THOMPSON, 1998, p. 184).
\end{abstract}

Vale considerar que a cultura não é uma "coisa" ou meramente "algo", a oralidade nos possibilita compreender os sentidos mais que profundos das subjetividades dos povos originários, pois o contrário disso resulta em um dos principais obstáculos de não reconhecimento do outro e de afirmação dos processos de colonização, que não aceitam reconhecer as singularidades étnicas, portanto, um ethos da pluralidade. Os povos originários tem muito a nos ensinar, ou nós temos muito a aprender, pois a modernidade trouxe consigo o desafio de viver a pluralidade, a diversidade e a coletividade, grandes dilemas que acompanham as relações até o tempo presente.

A modernidade, segundo Silva (2007, p. 63), trouxe "uma imensa dificuldade de reconhecermos em nós e nos outros o valor-pessoa". Precisamente, tal forma de pensar nos apresenta um dos desafios mais complexos, que é o viver em comunidade, como um "tipo de mundo que não está, lamentavelmente, ao nosso alcance - mas no qual gostaríamos de viver e esperamos vir a possuir [...] é nos dias de hoje, outro nome do paraíso perdido - mas a que esperamos ansiosamente retornar, e assim buscamos febrilmente os caminhos que podem levar-nos até lá" (BAUMAN, 2003, p. 09). O povo Kaingang tem se manifestado publicamente em favor de serem chamados enquanto comunidades, e não mais como aldeia ou reserva. Pensar neste sentido comunitário Kaingang, implica pensar no ethos da pluralidade e coletividade.

Dadas as condições de uma supremacia do ethos eurocêntrico, o povo Kaingang guarda com fidelidade a sua cosmologia, e segue, mesmo com as barreiras impostas, mantendo e salvaguardando a sua cultura, depois dos desafios vividos a partir do contato com o colonizador (VEIGA, 1994). Trata-se de pensar que a própria construção do ethos histórico, a partir da oralidade resultou em '[...] dialogar com 'o outro', e dessa forma, fazer história

(C) ETD-Educação Temática Digital Campinas, SP v.23 n.3 p. 677-696 jul./set.2021


oral indígena, então, é realizar essa tarefa de maneira mais profunda possível, pois se trata de contatar 'o outro' no sentido do pleno da conceituação cultural' (FREITAS, 2004, p. 187).

Nesse ethos da pluralidade, acredita-se que a responsabilidade se expressa no reconhecimento da alteridade, quando face-a-face se criam laços de sensibilidade e acolhida entre os indígenas e não indígenas, ou seja, reconhecendo-os e aceitando-os em suas diferenças. Isto ocorre, sem dúvidas, "na experiência do diálogo, constitui-se entre mim e o outro um terreno comum, meu pensamento e o dele formam um só tecido, minhas falas e as dele são invocadas pela interlocução, inserem-se numa operação comum da qual nenhum de nós é o criador" (MERLEAU PONTY, 1945, p. 81). Por sua vez, o diálogo torna-se o ponto de encontro entre os não indígenas e indígenas, trata-se da aproximação entre os diferentes, e em suas condições de construção do ethos histórico, abrem-se para constituir um ethos da comunidade.

\section{MÉTODO}

Dada a complexidade que envolve a reflexão sobre a constituição do ethos indígena, de modo mais direcionado o do povo Kaingang, o delineamento metodológico desta reflexão, adota a abordagem qualitativa que, enquanto exercício de pesquisa, permite que a imaginação e a criatividade levem os investigadores a propor trabalhos que explorem novos enfoques (YÁZIGI, 2005). Sabe-se que a pesquisa qualitativa tem foco na compreensão e explicação da dinâmica das relações sociais e nesse caso específico, as relações socioespaciais.

A pesquisa não objetiva representatividade numérica, mas, o aprofundamento da compreensão de um grupo social e das relações que estabelece com o lugar onde vive. Enquanto procedimentos metodológicos para a obtenção dos dados utilizou-se a História Oral e para reflexão, optou-se pela análise de discurso com base no referencial teórico previamente exposto. A História Oral consiste em uma prática de apreensão de narrativas realizada, sempre que possível, utilizando instrumentos eletrônicos de gravação, destinada a recolher testemunhos e promover análises de processos sociais do presente. Assegura-se que ela contribui na construção de uma visão mais concreta da dinâmica de funcionamento da trajetória do grupo social que se pretende estudar, além de ser um procedimento destinado à constituição de novas fontes para a pesquisa histórica, com base nos relatos orais colhidos sistematicamente em pesquisas específicas, sob métodos, problemas e pressupostos teóricos explícitos (LOZANO, 2002).

A perspectiva de dar igual valor à fonte escrita e à fonte oral e o anseio de ouvir o que os indígenas falam sobre si mesmos, sua comunidade e o lugar onde vivem, constituem o cerne do interesse pelo uso da história oral, especialmente no que tange o objeto de estudo, haja vista a representatividade da tradição oral entre os Kaingang, tornando a história oral

(C) ETD-Educação Temática Digital Campinas, SP v.23 n.3 p. 677-696 jul./set.2021


fundamental para a compreensão do seu modo de viver. Para a obtenção dos relatos de história oral e a análise das narrativas derivadas desse procedimento metodológico constroem as subjetividades tanto dos participantes da pesquisa quanto do próprio pesquisador, conferindo às análises um caráter contextual. As reflexões e constatações sobre pesquisa só têm coerência se situados neste espaço físico delimitado e na contemporaneidade. Para Portelli (1997) destaca que o relato oral tem tanta importância quanto a fonte escrita, compondo ambos a história de forma complementar. Paralelamente aponta que alguns significados e conotações sociais são irreprodutíveis na escrita, isto é, na transcrição de uma fonte oral. Assim, o material escrito a partir da oralidade sempre está influenciado pelas palavras e pelo olhar de quem o escreveu.

Trata-se de uma técnica que exige uma sequência de procedimentos, conforme destaca Meihy (1996) em seu livro Manual de História Oral. O primeiro passo é a elaboração de um projeto, para que se tenha clareza do que se quer pesquisar e os relatos não se transformem em histórias nostálgicas apenas, mas no registro da memória com um objetivo claro. No segundo passo, sugere-se que seja feita a escolha dos atores que irão contribuir na pesquisa, definidos com base naquilo que se quer descobrir, conforme ilustra o Quadro 01:

QUADRO 01. Caracterização dos grupos de participantes da pesquisa

\begin{tabular}{|c|c|c|c|c|}
\hline Grupo & Características comuns & $\begin{array}{l}\text { Média } \\
\text { Etária }\end{array}$ & $\begin{array}{l}\text { N. de } \\
\text { pessoas }\end{array}$ & Foco dos relatos \\
\hline $\begin{array}{c}\text { Grupo } \\
01\end{array}$ & $\begin{array}{l}\text { Pesquisadores junto às comunidades } \\
\text { indígenas na região oeste do Estado de } \\
\text { Santa Catarina }\end{array}$ & 56 anos & 4 & $\begin{array}{l}\text { Educação escolar, aspectos } \\
\text { culturais Kaingang. }\end{array}$ \\
\hline $\begin{array}{c}\text { Grupo } \\
02\end{array}$ & $\begin{array}{l}\text { Lideranças e Anciãos das comunidades } \\
\text { indígenas da região }\end{array}$ & 60 anos & 6 & Práticas culturais cotidianas. \\
\hline $\begin{array}{c}\text { Grupo } \\
03\end{array}$ & Mulheres indígenas & 33 anos & 10 & $\begin{array}{c}\text { Práticas culturais cotidianas, } \\
\text { educação infantil, ervas } \\
\text { medicinais }\end{array}$ \\
\hline $\begin{array}{c}\text { Grupo } \\
04\end{array}$ & Professores e professoras indígenas & 35 anos & 6 & $\begin{array}{l}\text { Educação escolar, relação } \\
\text { com a natureza. }\end{array}$ \\
\hline
\end{tabular}

Fonte: Elaboração dos autores

Nesta pesquisa, foram entrevistados pesquisadores do povo Kaingang da região oeste de Santa Catarina (Grupo 01), representantes das terras indígenas da região (Grupo 02), que relatam temas específicos da cultura, explicam sobre o cotidiano nas suas comunidades e sobre o modo Kaingang de viver e ensinar, grupos de mulheres Kaingang (Grupo 03) e professores e professoras indígenas (Grupo 4). 
O terceiro passo é a entrevista em si, que foi agendada com os colaboradores e gravada. 0 material audiovisual foi transcrito ${ }^{5}$ e posteriormente analisado com foco nos objetivos que se pretende atingir. Por fim, o documento das transcrições é estudado com base na análise de discurso, que "supõe um sistema significante, mas supõe também a relação deste sistema com sua exterioridade já que sem história não há sentido, ou seja, é a inscrição da história na língua que faz com que ela signifique" (ORLANDI, 1994, p. 53), destacando a dimensão simbólica e relacional dos fatos externados pelos participantes.

A estratégia desenhada para a aplicação desse procedimento metodológico precisou ser adaptada de acordo com o grupo de participantes. Com o Grupo 01, foi possível seguir todos os passos propostos: o agendamento prévio, gravação e transcrição dos relatos e os diálogos duraram entre 60 e 100 minutos. Quando a pesquisa foi realizada com os integrantes das comunidades indígenas a sequência de ações precisou ser flexibilizada a fim de respeitar os colaboradores e colher as informações pretendidas.

Apesar da relação prévia estabelecida entre pesquisadores e comunidades, a maioria dos indígenas mudava de comportamento quando o relato começava a ser gravado. Algumas pessoas solicitaram para conversar informalmente, sem gravação, o que por um lado, dificultou a transcrição dos dados e criou a urgência quanto à tomada de notas sobre cada um dos diálogos. Por outro lado, a flexibilização do procedimento gerou mais conforto e deixou os participantes à vontade para declarar o que pensavam acerca das temáticas discutidas.

Cabe destacar ainda que para preservar o anonimato dos colaboradores deste estudo, optou-se por ocultar os nomes dos entrevistados, substituindo os mesmos pela identificação do grupo ao qual pertencem (G1, G2, G3 ou G4) e uma inicial alfabética para identificação dos sujeitos (Sujeito 1 - A, Sujeito 2 - B, e assim por diante), resultando na seguinte menção ao final dos fragmentos da transcrição das falas: G1-A, G1B, G2-C, G3-D e G4E.

\footnotetext{
${ }^{5}$ As transcrições dos relatos de história oral estão disponíveis em DILL (2021).

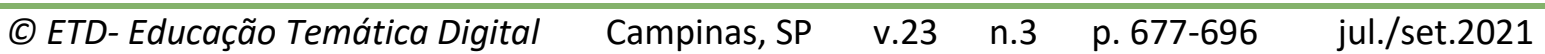




\title{
5 RESULTADOS
}

Para construção dessa etapa considerou-se na interpretação das Oralidades a partir dos seguintes critérios: A) Leitura das transcrições das oralidades; B) Reflexões das oralidades; C) Relações entre oralidades e literatura especializada. A técnica da História Oral nos possibilitou pensar as seguintes categorias para a constituição do ethos Kaingang.

\subsection{Por um ethos da Territorialidade e do Território do povo Kaingang}

A territorialidade para o povo Kaingang é tão importante quanto o território, um precisa do outro, assim como as metades clânicas. É importante termos a compreensão sobre o sentido da terra para o povo Kaingang, pois é nela que, culturalmente, o umbigo da criança é enterrado quando nasce, estabelecendo um vínculo eterno com o lugar. Por isso, "a territorialidade não provém do simples fato de viver num lugar, mas da comunhão que com ele mantemos" (SANTOS, 1993, p. 62). O povo Kaingang vive isso com intensidade, muito diferente dos fog (brancos), que não possuem essa sensibilidade com o lugar onde vive, podendo comercializar a terra e mudar com facilidade para outro espaço geográfico. Trata-se de uma relação ontológica, a territorialidade é isso, é para além da própria geografia que nasceu, pois nela carrega-se o ethos da plenitude.

Por isso, se considera que a terra é uma conquista de sangue, dado todo o processo de colonização e violência, por parte de quem sempre os expulsou na constituição do ethos histórico. No fragmento transcrito abaixo, percebe-se como os Kaingangs possuem trajetórias de luta.

\begin{abstract}
Para os indígenas da Terra Chimbangue, como houve luta pela demarcação de uma terra tradicionalmente ocupada, original, com alguns princípios desde o início, não foi uma terra dada, dada entre aspas, eles tiveram que lutar por ela. Eles começam lutando pela terra ainda no passado, com a ajuda de uma senhora chamada Dona Ana. Com a ajuda de antropólogos e simpatizantes, reconquistam essa terra tradicional, mesmo com a interferência de uma cultura fog que os segurou por muito tempo, como pessoas agregadas, peões, eles ficaram aos arredores dessas terras. Vão se constituindo e logo conseguem de volta as suas terras, no caso da Sede Trentin. (G1-A)
\end{abstract}

Nessa questão de território, se destaca como sendo a geografia dos Kaingang, as terras dos municípios de Chapecó, Ipuaçu e Entre Rios, localizadas no estado de Santa Catarina. Cabe mencionar que a Região Sul do Brasil possui, segundo dados do IBGE (2010) aproximadamente 77,773 mil indígenas, deste montante, 37.470 são pertencentes à etnia Kaingang.

Segundo Fernandes e Piovezana (2015, p. 115) "o senso comum revela a razão etnocêntrica e preconceituosa que cerca a realidade indígena brasileira. Dois extremos: de um lado, a sensação, sempre presente, de que os índios do sul não são mais índios", está 
enraizado no ethos histórico, uma visão colonizadora de mundo que considera esses indígenas como não civilizados e sem direito às suas próprias terras. Pois do outro extremo, existe "a conviç̧ão de que esses índios são aproveitadores, indigentes do social e exploradores do natural" (FERNANDES; PIOVEZANA, 2015, p. 115), portanto, para que demarcação das terras indígenas? Elas devem pertencer aqueles que produzem, que lucram, que contribuem com o desenvolvimento econômico, ou seja, a elite branca.

Ainda segundo os autores, os Kaingang são vistos como "o bom selvagem, por estas bandas, é mito que não se atualizou. Ser índio no sul é, na versão hardcore do senso comum, ser vagabundo; é contar com a tutela generosa da FUNAl; é poder dispor de terras e os recursos naturais à vontade" (FERNANDES; PIOVEZANA, 2015, p. 115). Tais adjetivos, infelizmente reforçam um olhar preconceituoso do ethos histórico, construído principalmente pelo projeto colonizador, que ainda segue o seu curso.

Sem território e territorialidade, não existem saberes, cosmologias e muito menos um ethos educativo, pois são nestes espaços que a vida dos povos originários se faz morada habitada por todos os seres da natureza.

\subsection{Por um ethos da linguagem do Povo Kaingang}

Para os povos indígenas o que mantém vivo a constituição do ethos é a apropriação e dominação da própria língua. Trata-se de um saber cultural que precisa ser aprendido e partilhado entre as gerações, pois o contrário disso, resulta em destruição do próprio ethos histórico.

Importante situar que, antes da chegada dos portugueses no Brasil, falavam-se milhares de idiomas, e desde o último censo, o Brasil preserva 305 povos indígenas e 274 línguas originárias (IBGE,2010). A linguagem para o povo Kaingang, é mais que um mecanismo de comunicação, apresenta uma cosmologia cheia de sentidos e significados. Tem muitas palavras em Kaingang que não possuem tradução e significado no idioma português. $\mathrm{Na}$ transcrição que segue, percebe-se que os desafios vividos para preservar a língua originária.

Pra mim, algumas coisas são fundamentais pra preservar a cultura, a principal é a língua, que precisamos ensinar os pequenos na escola, daí chegam em casa os pais falam também o Kaingang, isso é fundamental. Outra coisa são as nossas comidas típicas, as ervas medicinais, ensinar e saber como fazer os remédios, pra que serve cada planta e isso é que a gente sempre conversa e reforça na comunidade pra mandar o ser Kaingang. (G3-A)

Segundo dados do IBGE (2010), a língua Kaingang que é da família linguística MacroJê, considera que em torno de 22.027 indígenas são falantes do idioma Kaingang, esse número não considera crianças com menos de 5 anos. As crianças Kaingang na grande maioria, aprendem o português somente na escola, pois aprender esse idioma é assegurar a 
possibilidade de constituição do ethos e de resistir aos processos bárbaros de colonização, construindo condições de liberdade e abrindo-se para um ethos da decolonização. É através da língua que muito da cosmologia poderá ser repassada, que os cantos poderão ser ensinados, os rituais e tudo que permeia a cosmologia do povo. No relato que segue, evidencia-se essa preocupação e importância.

No meu modo de ver uma das principais coisas que a gente tem que preservar é a oralidade, as contações dos mais velhos pros mais novos, a própria forma de cuidado $e$ de organização do povo, a questão da língua é muito importante, dos conhecimentos dos mais velhos quanto à produção de artesanato, do manejo, da coleta e do preparo das plantas medicinais, a própria forma de organização da comunidade, a forma de buscar o resgate pela prática dos rituais. Pra nós a questão do ritual do batismo é muito forte e bem importante. (G3-C)

A linguagem é mais que uma forma de comunicar-se, é um ato de resistência, existência e luta. É na linguagem que reside a cosmovisão dos povos, os símbolos e sinais, seja através da palavra, do silêncio ou da escuta, tais aspectos constituem uma educação que ultrapassa a nossa compreensão.

\subsection{Por um ethos da Cosmologia Kaingang}

Quando se trata da origem no ethos Kaingang a percepção que se tem é de uma riqueza cultural singular. Na cosmologia do povo Kaingang, reside a vida, o sentido e o significado. O povo Kaingang mantém muito dos rituais e costumes realizados pelos seus ancestrais, isso evidencia a luta diante de um projeto que proibia e ocultava qualquer manifestação cultural praticada. Muitos agravantes ocorreram no decorrer dos séculos, e nas últimas décadas, conforme o relato abaixo, um dos agravantes do abandono dos rituais é a chegada de igrejas nas comunidades.

Um grande problema são as igrejas que entram nas Aldeias e proíbem essas manifestações e rituais. Individualizaram a fé e a vida, jogaram Topê (Deus) para o Céu, tiraram Deus das pessoas e da natureza. (G1-A)

O povo Kaingang guarda e preserva em sua cosmologia toda sabedoria tradicional, é uma espécie de "caixa de pandora". É nesta caixa que ficam guardados os rituais, o uso de plantas tradicionais e todo ethos comunitário. Conforme a observação de um professor(a) não indígena que trabalha com a cultura, observa-se claramente a percepção e compreensão de como é estabelecida essa relação.

A cultura Kaingang é fortemente marcante pelo fato de resistir e viver integrada com a cosmologia indígena. $O$ indígena tem o tempo da escuta, ele dificilmente fala sobre algo que lhe é perguntado se não tiver uma relação de confiança. Mesmo entre os integrantes da mesma cultura, existe um tempo de espera, os saberes tradicionais nem sempre são passados para os mais jovens se não passar pelo processo de merecimento. Outro fator visivel é a dimensão do tempo, os mesmos se equilibram no tempo chronos e kairós. (G1-C) 
Conforme mencionado acima, o fator de mediar e vivenciar o tempo, é uma constante marca na vida dos povos originários. O tempo chronos e kairós mediam a vida contemporânea dos Kaingangs. O kairós, no desejo de sentir e viver a natureza, os sentidos, o chronos, mediado pelo tempo mecânico, do relógio e calendários.

É possível observar nas comunidades Kaingangs do oeste de SC, alguns anciãos, chamados de kofag, que ainda falam a sua idade relacionando aos elementos da natureza. É comum ter os velhos sábios com mais de cem anos de idade. Os mesmos acabam falando que possuem por exemplo: 3 taquaras, ou três taquaras e meia. Essa medida apresentada, referese a floração da taquara. Esta unidade de tempo consiste na observação da floração da taquara, que ocorre exatamente a cada trinta anos. Quando os velhos dizem chegar perto da terceira floração da taquara, é porque estão chegando aos noventa anos de idade. A taquara é vida para o povo Kaingang, ela é utilizada para produção de artesanato, ornamentação e principalmente para esta unidade de medida de tempo (SANTOS, BATTESTIN, PIOVEZANA, 2018). É nesta relação com o tempo que se apresenta um ethos educativo inestimável, que muitas vezes foge a compreensão de quem vive outra cultura. Respeitar o tempo é fundamental para que ocorra a aprendizagem, por isso da importância de uma educação escolar indígena diferenciada.

A cosmologia Kaingang está totalmente ligada a natureza, é nela que vivem os sentidos, os significados e as motivações de respeito com a cultura. Por exemplo, o uso das metades clânicas, expressa uma perspectiva exogâmica, "denominadas de Kamé e Kairu, que mantém entre si relações assimétricas e complementares [...]. A cada uma dessas metades corresponde uma "marca" - pintura facial usada durante o ritual do kiki" (NACKE, 2007, p. 35). É neste ritual que ocorre o culto aos mortos, ou seja, o momento em que espíritos são encaminhados. No registro abaixo, observa-se que

Quando eles fazem o espaço para o ritual, tem que abrigar físico e espiritual, todas as pessoas convidadas das metades. O lugar sagrado escolhido tem a casa dos Kamé, dos Kairu, dos velhos (Kofa ag), dos sábios, e eles, mesmo que estejam dialogando com a natureza, dialogam entre as metades e em um tempo próprio, observam sinais e se localizam, escolhem um local pela harmonia de fenômenos sociocosmológicos. (G1-A) 
O ritual do $\mathrm{Kiki}^{6}$, as metades clânicas ${ }^{7}$, o uso das plantas, a escolha das plantas, as danças, as rezas, os alimentos utilizados para o ritual do kiki, fazem parte da cosmologia Kaingang. É aí que reside o ethos que acreditamos ser possível, um ethos que supera as amarras do colonialismo, um ethos educativo que apresenta um mundo cosmológico possível de ser mantido e vivido. Também, é nesta dinâmica que reside um cuidado com a vida em todas as suas instâncias. Educar para a morte, é um dos princípios para o povo Kaingang, pois é a partir desta compreensão cosmológica que as crianças passam a observar o movimento da vida ancestral.

\subsection{Por um ethos educativo do povo Kaingang}

Pensar em um ethos educativo a partir do povo Kaingang, é considerar que "a colonialidade é um dos elementos constitutivos e específicos do padrão mundial de poder capitalista" (QUIJANO, 2000, p. 342). E, por isso, trata-se de compreender que essa lógica da colonialidade ocorre na contramão de qualquer constituição de um ethos comunitário, pois, a legítima intenção do projeto eurocêntrico de educação é apropriar-se da cultura do outro, explorando e controlando saberes e epistemologias originárias.

Por isso, é atual a tese de que "a elaboração intelectual do processo de modernidade produziu uma perspectiva de conhecimento e um modo de produzir conhecimento que demonstram o caráter do padrão mundial de poder: colonial/moderno, capitalista e eurocentrado" (QUIJANO, 2005, p. 126).

A padronização do conhecimento também chegou nas escolas indígenas, nas comunidades, porém, com a presença de professores indígenas nas escolas, muito da forma de pensar e ensinar, acaba perpassando o rol dos conteúdos. A educação Kaingang está presente em toda comunidade, principalmente com o contato dos mais velhos. A importância de ter uma educação alicerçada com a cosmologia, é uma das preocupações do povo Kaingang. No testemunho abaixo é possível observar:

\footnotetext{
${ }^{6}$ O Ritual do Kiki, ou Culto aos Mortos é uma festa para os mortos recentes, que é organizada pelos consanguíneos do morto, em sua homenagem e integra durante o ritual as metades Kamé e Kairu. Esse culto é apontado como a base e a expressão mais forte da cultura espiritual dos Kaingang e a manutenção desse ritual, é fundamental para a manutenção da cultura desse povo (SILVA, 2011).

${ }^{7}$ O Povo Kaingang se organiza a partir de princípios sóciocosmológicos dualistas - A sociedade e toda a natureza estão tradicionalmente divididas em metades que se complementam, denominadas Kamé e Kairu, irmãos mitológicos (TOMMASINO; FERNANDES, 2001).
} 
A minha preocupação sobre nossa cultura, nossos costumes, nossa vivência, nossas marcas. Eu sou marca cumprida e minha esposa é marca redonda, então só não queremos acabar com nossa vivência, nós temos que ensinar nossos filhos, saber nossa cultura, as marcas e também um pouco que eu me preocupo, é que dentro de sala de aula, tem que existir nosso costume, nossa cultura e os professores tem que saber. Isso que é importante saber dentro de sala de aula pra não se esquecer nossos costumes. Eu sempre falo com minha filha que é mãe e é professora, que a gente tem que ensinar os filhos da gente, pra não perder nossa vivência, nossa cultura, isso também é muito importante. (G2-F)

Os anciãos são vistos com frequência nas escolas, seja para participar de alguma atividade ou fala com estudantes. Os velhos, como são chamados carinhosamente pelos Kaingangs, são importantes para a comunidade, pois é neles que reside toda sabedoria do povo. Por ora, conforme a transcrição abaixo, muitos já não compreendem esse movimento, principalmente quem não é indígena:

Quem entende a importância dos velhos, são pessoas que nem a gente, que tá em sala de aula, que se preocupa com a cultura, que conversa sobre isso, os outros são "cabeçudos". E vendo hoje a escola, a casa da gente, eles tentam trazer como era antes, mas tem alguns que falam: 'por que vocês tão estudando isso?'. Não entendem porque que é importante. Pra ter noção mesmo só quem tá estudando mesmo. (G2-A)

A educação Kaingang está alicerçada em toda cosmologia Kaingang, desde o nascimento, com a aprendizagem da língua materna, com os cantos, com a caça, com a contação de histórias e com o preparo dos alimentos tradicionais. A educação para o povo Kaingang, não se resume ao espaço escolar, ela é a própria vida em comunidade.

É inegável o valor da educação em seu sentido coletivo, essa tradição dos ensinamentos é passada através da oralidade entre as gerações, e de acordo com Piovezana (2007, p. 102), "todas as comunidades indígenas dispõem de seus próprios processos de socialização e de formação das pessoas". A oralidade é um destes processos de formação.

A oralidade e a palavra são princípios fundantes da educação Kaingang. É no conhecimento repassado de geração para geração que vive toda cosmologia do povo. É no tempo de espera, de escuta, de silêncio e respeito, que os saberes chegam, seja através da natureza ou dos anciãos. Esses são considerados princípios educativos, vividos em todas as instâncias da comunidade em diferentes espaços: seja ao redor do fogo; nas rodas de contação de histórias; na preparação dos alimentos; na confecção de artesanatos; nos cantos e rezas estão presentes inúmeras epistemes do povo Kaingang, que chamamos aqui, de ethos educativo. 


\section{CONSIDERAÇÕES FINAIS}

Pensar na constituição de um ethos educativo, e mais especificamente Kaingang, é considerar primeiro os aspectos que construíram a historicidade desse ethos, que em nossas percepções ocorreu por meio de relações violentas e dominadora dos processos de colonização e imposição de um ethos essencialmente eurocêntrico. Trata-se nessa via negativa da não aceitação do outro, da negação de ethos, compreender os caminhos que constituíram um pensamento colonial - horizontal, único, excludente, cujas consequências resultaram na própria destruição do ethos da comunidade dos povos originários.

Por isso, as reflexões sobre o ethos sinalizaram para a necessidade de construção de um ethos da comunidade, como possibilidade de "definição de uma autêntica comunidade universal de comunicação exige uma reflexão filosófica aprofundada sobre a relação do reconhecimento, sem a qual a comunicação se instrumentaliza e, finalmente se desumaniza" (VAZ, 1992, p. 71). Nesse contexto, considera-se a partir do ethos da comunidade, a própria dimensão da dignidade humana, que constitui-se "como relação que revela no outro a presença de uma dimensão axiológica fundamental: a dignidade em um outro EU?" (VAZ, 1992, p. 71). Para avançarmos na constituição de um ethos educativo, é fundamental que as relações intersubjetivas se construam no reconhecimento, que se abre para a reflexão de que um outro mundo é possível, pois já sinaliza Vaz que "O mundo é, para cada um de nós, o caminho para o encontro do outro" (1992, p. 74).

Trata-se de pensar em uma dimensão do consenso espontâneo constituído na relação intracomunitário entre o Eu e o Nós. Como sendo "a relação intersubjetiva no nível do consenso espontâneo especificada eticamente pela virtude da amizade". Segundo Vaz (1992, p. 78) "é esse o nível do existir-em-comum que podemos denominar intra-societário, e no qual se dá a passagem da sociedade convivial para a sociedade política". Esse nível do consenso reflexivo nas relações do Eu-Nós fundamenta-se pelas regras e leis constituídas para o bem da comunidade.

É nessa perspectiva que consideramos quatro dimensões do ethos, um ethos da Territorialidade e do Território, um ethos da linguagem, um ethos da Cosmologia e um ethos educativo do povo Kaingang, portanto, essa reflexão trata-se de um convite para pensar o nosso hoje. Diante disso, é necessário agir na construção de um ethos educativo, que assegure o valor da vida e do respeito em seu sentido mais profundo dos modos de vida e de um ethos da pluralidade.

É tempo, de aprender com as Vespas, em um dos estudos realizado por um grupo de pesquisadores da Sociedade Zoológica de Londres no Panamá, Bauman (2011) considerou em suas reflexões que as Vespas que saiam de seus ninhos originais, quando chegavam próximos a outros ninhos, eram recebidas como "legítimos membros do ninho". Tal tipo de

\begin{tabular}{|c|c|}
\hline (C) ETD-Educação Temática Digital & p. 677-696 \\
\hline
\end{tabular}


comportamento das Vespas, nos possibilita ainda mais entender a origem de um ethos da comunidade dos povos originários, que considera o reconhecimento do Outro. É tempo de aprender com os povos Kaingangs! É tempo de construir um ethos que seja capaz de salvaguardar a vida e o ethos educativo pode contribuir para a construção de uma vida em comunidade que pense e cuide do presente e futuro.

\section{REFERÊNCIAS}

ANCHIETA, José de. Cartas, informações, fragmentos históricos e sermões do padre José de Anchieta: 1554-1594. Rio de Janeiro: Ed. Civilização Brasileira, 1933.

ARROYO, Miguel G. Outros sujeitos, outras pedagogias. Petrópolis, RJ: Vozes, 2012.

BAUMAN, Zygmunt. Vida líquida. Trad. Carlos Alberto Medeiros. 2.ed. Rio de Janeiro: Jorge Zahar Ed.,2009.

BAUMAN, Zygmunt. Comunidade: a busca por segurança no mundo atual. Trad. Plínio Dentzien. Rio de Janeiro: Zahar, 2003.

BAUMAN, Zygmunt. Modernidade líquida. Tradução Plínio Dentzien. Rio de Janeiro: Jorge Zahar Ed., 2001.

BAUMAN, Zygmunt. A ética é possível num mundo de consumidores? Trad. de Alexandre Werneck. Rio de Janeiro: J. Zahar, 2011.

DILL, Fernanda Machado. Caderno de campo: técnicas e notas de pesquisa sobre o povo Kaingang. Curitiba: Insigth. 2021.

DOM JOÃO III. Regimento de 1549. In: RIBEIRO, Darcy; MOREIRA, Neto e ARAUJO, Carlos de (orgs.). A fundação do Brasil. Petrópolis, Vozes, 1992.

FERNANDES, Ricardo Cid; PIOVEZANA, Leonel. Perspectivas Kaingang sobre o direito territorial e ambiental no sul do Brasil. Ambient. soc. [online]. 2015, vol.18, n.2, pp.111-128.

INSTITUTO BRASILEIRO DE GEOGRAFIA E ESTATÍ́STICA. Censo Demográfico 2010 Características gerais dos indígenas. Disponível em:

https://censo2010.ibge.gov.br/terrasindigenas/ Acesso em: 30 de Janeiro de 2021.

FREITAS, Edinaldo. Fala de índio, história do Brasil: o desafio da etno-história indígena. História Oral, São Paulo, n. 7, p. 181-97, jun. 2004.

GOMES, Nilma Lino. Diversidade étnico-racial, inclusão e equidade na educação brasileira: desafios, políticas e práticas. RBPAE - v.27, n.1, p. 109-121, jan./abr. 2011.

GEERTZ, C. Dilemas de la cultura: antropologia, literatura y arte en la perspectiva posmoderna. Barcelona: Gedisa. 2001. 
LOZANO, J. E. Prática e estilos de pesquisa em história oral contemporânea. In: M. D. FERREIRA, Usos \& abusos da história oral. 5.ed. Rio de Janeiro: Editora FGV, 2002. p. 15-25.

KUPER, A. Cultura, diferença, identidade. In: A. KUPER, Cultura: a visão dos antropólogos. Tradução Mirtes Frange de Oliveira Pinheiros (p.287-318). Bauru: EDUSC. 2002.

MEIHY, J. C. Manual de história oral. São Paulo: Edições Loyola, 1996.

MINAYO, M. C. Pesquisa social: teoria, método e criatividade. Petrópolis: Vozes, 2001.

MORIN, Edegar. 0 método 5: a humanidade da humanidade. Trad. Juremir Machado da Silva. 4. ed. Porto Alegre: Sulina, 2007. 309p.

NACKE, Aneliese. Os Kaingang: passado e presente. In: NACKE, Aneliese...et al. Os Kaingang no oeste catarinense: tradição e atualidade. Chapecó: Argos, 2007.

PIOVEZANA, Leonel. A educação no contexto indígena Kaingang. In: NACKE, Aneliese...et al.Os Kaingang no oeste catarinense: tradição e atualidade. Chapecó: Argos, 2007.

PORTELLI, A. O que faz a história Oral diferente. Proj. História, n.14, 1997.

QUIJANO, Aníbal. "Colonialidad del poder y clasificación social”. Journal of world-systems research, v. 11, n. 2, 2000, p. 342-386.

QUIJANO, Anibal. Colonialidade do poder, eurocentrismo e América Latina; A colonialidade do saber: eurocentrismo e Ciências Sociais. Perspectivas latino-americanas. Buenos Aires: CLACSO, 2005.

RIBEIRO, Darcy. O povo brasileiro: a formação e o sentido do Brasil. São Paulo: Companhia das Letras, 2006.

SANTOS, Milton. Por uma outra globalização - do pensamento único à consciência universal. Rio de Janeiro: Ed. Record RJ, 1993.

SANTOS, Jorge A.; BATTESTIN, Cláudia.; PIOVEZANA, Leonel. Paradojas interculturales en la formación de profesores indígenas del pueblo Kaingang. Rev. Diálogo Educ., Curitiba, v. 18, n. 59, p. 1222-1241, out./dez. 2018.

SAVIANI, Dermeval. História das ideias pedagógicas no Brasil. Campinas: Autores Associados, 2011.

SILVA, L. A. A história Kaingang através do Ritual do Kiki. Santa Catarina em História, 11-23. 2011.

TOMMASINO, K., FERNANDES, R. C. Kaingang. Povos indígenas no Brasil, 2010. Disponível em: http://pib.socioambiental.org/pt/povo/kaingang/288 . Acesso em: 16 de fevereiro de 2016.

TYLOR, E. Primitive Culture. Londres: John Mursay \& Co. 1958. 
VAZ, Henrique de Lima. Antropologia Filosófica II. São Paulo: Loyola, 1992.

VAZ, Henrique de Lima. Ética e cultura. 4. ed. São Paulo: Loyola, 2004.

VAZ, Henrique de Lima. Raízes da modernidade. São Paulo: Loyola, 2002.

VEIGA, J. Organização Social e cosmovisão Kaingang: uma introdução ao parentesco, casamento e nominação em uma sociedade Jê Meridional. Dissertação (Mestrado em filosofia) - Instituto de Filosofia e Ciências Humanas, Universidade Estadual de Campinas, 1994.

YÁZIGI, E. Deixe sua estrela brilhar: criatividade em ciências humanas e no planejamento. São Paulo: CNPQ. 2005.

Revisão gramatical por: Rosangela Medeiros Fachel

E-mail: rosangelafachel@gmail.com 